\title{
Ponderación de la eficiencia y eficacia de la solución de conflictos por nombres de dominio .MX en las vías alternativa y contencioso-administrativa
}

\author{
$* * * *$ \\ Vanessa Chávez Zárate \\ Universidad Michoacana de San Nicolás de Hidalgo \\ vanessa.ch.lex@gmail.com
}

Recibido: 2 de abril de 2021

Aceptado: 16 de junio de 2021

\section{Resumen}

El objetivo principal de este artículo es determinar el grado de eficiencia y eficacia de la vía administrativa alternativa frente a la vía contencioso-administrativa en relación con la resolución de los conflictos por nombres de dominio .MX y la protección de los derechos marcarios y de propiedad industrial.

Para determinar la eficiencia y eficacia, es decir, el costo, tiempo y logro del resultado, se realiza una ponderación basada en las ventajas y desventajas de la utilización de ambas vías, las cuales tienen características particulares. Lo que permite la comparación y determinación de sus características es su similitud teórica, legal y procesal. Diversos teóricos han mostrado que la resolución de los conflictos es compleja, tiene un alto costo y poca celeridad en la vía contenciosa o jurisdiccional; por otro lado, es sencilla, económica y rápida en la vía alternativa, lo que es de suma importancia estudiar y determinar.

La solución a los conflictos por nombres de dominio. MX que vulneran derechos de terceros se puede dar en distintas vías. En este caso, en la vía administrativa alternativa o extrajurisdiccional, a través de los mecanismos alternativos de solución de controversias en materia de propiedad intelectual que señala la legislación mexicana y los métodos alternativos ofrecidos por los proveedores de servicios de 
resolución de disputas, así como la vía contencioso-administrativa o jurisdiccional, que tiene lugar después de haber agotado una vía previa, acorde al fundamento de la Ley Federal de Protección a la Propiedad Industrial.

El resultado de la ponderación ha mostrado que ambas vías tienen eficiencia y eficacia, sin embargo, una en mayor grado que la otra, tomando en cuenta las características e indicadores determinados en este artículo.

Palabras clave: autoridades, propiedad industrial, infracción administrativa, defensa legal, tasas.

\title{
Weighting of the Efficiency and Effectiveness of Conflict Resolution for .MX Domain Names in the Alternative and Contentious-Administrative Routes
}

\begin{abstract}
The main objective of this article is to determine the degree of efficiency and effectiveness of the alternative administrative route compared to the contentious-administrative route, in relation to the resolution of conflicts over .MX domain names, and the protection of landmarks and property rights industrial.

To determine the efficiency and effectiveness, that it, the cost, time and achievement of the result, a weighting is made based on the advantages and disadvantages of using the two routes, which have particular characteristics. It allows the comparison and determination of their characteristics is their, theoretical, legal and procedural similarity.

Several theorists have shown that conflict resolution is complex, has a high cost, and at one point a speed in the litigious or jurisdictional way; on the other hand, it is simple, cheap and fast in an alternative way, which is of the utmost importance to study and determine.

The resolution of conflicts over.MX domain names that violate the rights of third parties can be done in different ways. In this case, the alternative or extra-jurisdictional administrative route, through the alternative mechanisms for the resolution of disputes in the field of intellectual property that Mexican legislation indicates and the alternative methods offered by the providers of dispute resolution services, also through of Contentious-administrative or jurisdictional litigation, which is carried out after exhausting a previous route, according with the Federal Law for the Protection of Industrial Property.

The result of the weighting has shown that both routes are efficient and effective, however, one even more than the other, taking into account the characteristics and indicators determined in this article.
\end{abstract}

Key words: authorities, industrial property, administrative infringement, legal defense, rates. 


\title{
Ponderação da eficiência e eficácia da resolução de conflitos para nomes de domínio .MX em canais administrativos alternativos e contenciosos
}

\begin{abstract}
Resumo
O objetivo principal deste artigo é determinar o grau de eficiência e eficácia da via administrativa alternativa em relação à via contencioso-administrativa em relação à resolução de conflitos sobre nomes de domínio .MX e à proteção de marcas e direitos de propriedade industrial.

Para determinar a eficiência e eficácia, ou seja, o custo, o tempo e o alcance do resultado, é feita uma ponderação com base nas vantagens e desvantagens da utilização de ambas as rotas, que apresentam características particulares. O que permite a comparação e a determinação de suas características é sua semelhança teórica, jurídica e processual.

Vários teóricos têm mostrado que a resolução de conflitos é complexa, tem alto custo e pouca rapidez na forma contenciosa ou jurisdicional; por outro lado, é simples, barato e rápido no percurso alternativo, que é de extrema importância estudar e determinar.

A solução para conflitos sobre nomes de domínio .MX que violam os direitos de terceiros pode ser dada de diferentes maneiras. Neste caso, na via administrativa alternativa ou extrajudicial, por meio dos mecanismos alternativos de solução de controvérsias no campo da propriedade intelectual indicados pela legislação mexicana e os métodos alternativos oferecidos pelos prestadores de serviços de solução de controvérsias, bem como o Percurso contencioso-administrativo ou jurisdicional, que se realiza após esgotamento de percurso anterior, de acordo com os fundamentos da Lei Federal de Proteção à Propriedade Industrial.

$\mathrm{O}$ resultado da ponderação mostrou que ambas as rotas são eficientes e eficazes, porém, uma em maior grau que a outra, atendendo às características e indicadores determinados neste artigo.
\end{abstract}

Palavras-chave: autoridades, propriedade industrial, infração administrativa, defesa legal, honorários.

\section{Introducción}

Este artículo contribuye a determinar el grado de eficiencia y eficacia que tiene la utilización de la decisión de experto y el juicio contencioso-administrativo para resolver los conflictos por nombres de dominio .MX, que por lo regular suelen invadir derechos de terceros, titulares de marcas, pero también afectan otros derechos. La eficiencia y eficacia se traduce en parámetros de medición como tiempo, 
costo y logro del resultado. También se muestran las características de las vías alternativa y contenciosa para hacer una ponderación de las ventajas y desventajas de estas.

Los titulares de derechos de propiedad industrial tienen acceso a distintos medios legales para la defensa de sus derechos a nivel internacional y nacional, con fundamento en diversas normas legales. La legislación ha presentado cambios significativos y esto se debe a los nuevos retos que trae consigo el entorno online. Con ello se amplía la observancia y protección de los derechos de propiedad intelectual, dando una respuesta mayor, sobre todo, en relación con los conflictos por nombres de dominio que infringen derechos de terceros.

Una de las cuestiones importantes que se han suscitado en los últimos quince años en algunos debates sobre la propiedad intelectual a nivel internacional ha sido la relación entre los nombres de dominio y algunas figuras de la propiedad intelectual, que suelen ser invadidas en el entorno electrónico por el registro y uso de nombres de dominio, lo que va cada vez más en aumento. En un inicio, esta problemática impactaba solo en la protección de las marcas, pero después se extendió a los avisos comerciales, las denominaciones de origen y las reservas de derechos al uso exclusivo en el caso mexicano, es decir, esta problemática enfrenta en conflicto a dos o más derechos de propiedad intelectual.

Los conflictos por ciberocupación antes descritos -comúnmente asociados al aprovechamiento de marcas- se pueden resolver en distintas vías: 1) la vía administrativa; 2) la vía contencioso-administrativa; y 3) la vía administrativa alternativa o extrajurisdiccional. Aquí solo se analizan la segunda y tercera, empero, no esta de más mencionarlas a todas.

Cabe aclarar que se usa el término "vía administrativa alternativa" como sinónimo de "decisión de experto" (que, en el caso de .MX, se rige por la política de solución de controversias en materia de nombres de dominio para .MX, o LDRP, y su Reglamento), la cual se desarrolla a través de un procedimiento alternativo, y se usa la expresión "vía contencioso-administrativa" como sinónimo de "juicio contencioso-administrativo" (que se rige por la Ley Federal de Procedimiento Contencioso Administrativo).

En México, en la Ley Federal de Protección a la Propiedad In- 
dustrial, la inclusión de la infracción administrativa por el uso de nombres de dominio como marcas muestra la importancia de la regulación de los nombres de dominio. Forma nuevos criterios para la protección marcaria ante la ciberocupación, la que seguramente irá en aumento, y, a su vez, amplía los medios de defensa de los titulares de las marcas en el ámbito administrativo y contencioso-administrativo a nivel nacional.

La cuestión de los mecanismos alternativos de solución de controversias en materia de propiedad intelectual a nivel nacional es todavía poco explorada, pero resulta eficiente y eficaz para la solución de conflictos comerciales, como los que surgen por nombres de dominio cuando estos últimos suelen invadir derechos de terceros.

Es sumamente relevante establecer que tanto la vía alternativa como la contenciosa son eficaces y eficientes, pero una en mayor grado que la otra. Cada una tiene sus propias características, las cuales ayudarán a mostrar sus ventajas o desventajas, y dependiendo del caso y de las circunstancias en general, serán o no aplicables. Para poder definir un criterio de preferencia entre una u otra es necesario establecer una serie de elementos, los cuales se aportan en este artículo.

Diversos teóricos han mostrado que la vía alternativa es preferible sobre la contenciosa o jurisdiccional, no solo por tener un mayor desarrollo o más ventajas mostradas en distintos estudios, sino también porque la vía contenciosa puede generar una situación reconocida doctrinalmente: el hecho de que resulta "mejor" para el titular de una marca comprar sus derechos a quien registró un nombre de dominio de mala fe (el "ciberocupa"), al que este titular tenía derecho en primer lugar, en vez de acudir a la vía legal para tratar de recuperarlos. La anterior situación es lo que pone en la mira a la vía administrativa alternativa como más eficiente y eficaz en virtud de los costos, tiempo y resultado; además, ayuda a uniformar la legislación en los conflictos internacionales por el uso y registro de nombres de dominio de mala fe.

El artículo se ha dividido en dos partes: en la primera, se muestran los detalles del alto grado de eficiencia y eficacia que tiene la vía alternativa en comparación con la vía jurisdiccional en relación con la resolución de conflictos por nombres de dominio .MX; en la segunda, se analiza la vía contenciosa, mostrando su eficiencia y 
eficacia en relación con la vía alternativa, y se concluye con la determinación de las ventajas y desventajas de cada una.

Con lo anterior se establecen algunas particularidades que pueden incidir en la ponderación de cuál es la mejor vía para proteger los derechos de propiedad industrial ante el abuso por el uso y registro de nombres de dominio .MX.

\section{Eficiencia y eficacia de la vía administrativa alternativa}

Para determinar la eficiencia de la vía alternativa en la resolución de conflictos por nombres de dominio hay dos parámetros fundamentales a evaluar: el costo y el tiempo. Para determinar la eficacia, que comúnmente se asocia con el efecto deseado, se debe analizar el logro del resultado.

Aludir a una vía administrativa alternativa, es decir, a una solución alternativa, es hablar de diversos métodos alternativos de solución de controversias: mediación, conciliación, arbitraje y decisión de experto.

Los mecanismos alternativos de solución de controversias (MASC), o métodos alternativos de solución de disputas (alternative dispute resolution, o ADR, por sus siglas en inglés), "son herramientas útiles y flexibles que diversifican las vías de acceso a la justicia" (López Ayllón, 2015, p. 22), los cuales poco a poco han ido mostrando sus ventajas o beneficios frente a las opciones tradicionales o jurisdiccionales, lo que hace sumamente sencillo alentar a su utilización, sin embargo, es importante desarrollar algunas ideas.

En materia comercial, y especialmente en propiedad intelectual, los métodos alternativos son sumamente utilizados, sobre todo aquellos prestados internacionalmente por el Centro de Arbitraje y Mediación de la Organización Mundial de la Propiedad Intelectual (OMPI), el cual ofrece servicios de "arbitraje, mediación y decisión de experto" (Organización Mundial de la Propiedad Intelectual, s.f.-b). Son particularmente útiles en la solución de conflictos nacionales y los que transcienden las fronteras de cada país.

En 2014, la OMPI y el Instituto Mexicano de la Propiedad Industrial (IMPI) celebraron un memorándum de entendimiento, que parece similar a un convenio de cooperación y colaboración, en el 
cual se le delegan facultades a la OMPI para que esta lleve a cabo la prestación de métodos alternativos de solución de controversias (Margáin y Gurry, 2014, pp. 2-3).

En el caso mexicano, los MASC se han ido incorporando poco a poco a la legislación de propiedad intelectual. Para ejemplificar, se permitió la conciliación desde la Ley de la Propiedad Industrial, que fue derogada recientemente por la Ley Federal de Protección a la Propiedad Industrial y en la cual se le dio mayor desarrollo al procedimiento conciliatorio, también al arbitraje, pero como un procedimiento en materia de comercio, regulado por el Código de Comercio mexicano. Por otra parte, en materia de derechos de autor, se incorporó aproximadamente hace nueve ańos el procedimiento de avenencia y el arbitraje $^{1}$ en aplicación de la Ley Federal del Derecho de Autor.

El IMPI, organismo competente para la protección del sistema de propiedad industrial en México, funge como conciliador en las declaraciones administrativas de infracción, es árbitro en la resolución de controversias y determina el pago de dańos y perjuicios derivados de la violación a los derechos de propiedad industrial relacionados con las infracciones. Lo anterior se podría considerar como una afectación a la neutralidad de la decisión o intervención, porque es el mismo órgano el que resuelve y concilia, lo que podría ser una desventaja en el uso de estos mecanismos alternativos.

"Aunque las controversias en materia de propiedad intelectual pueden resolverse ante los tribunales, las partes las someten cada vez con mayor frecuencia a la mediación, al arbitraje $\mathrm{u}$ otros procedimientos de solución alternativa de controversias" (Centro de Arbitraje y Mediación, 2016, p. 2), debido a sus ventajas en tiempo y costo en comparación con las opciones jurisdiccionales.

1 El Título XI, capítulo II de la Ley Federal del Derecho de Autor llama al método alternativo "procedimiento de avenencia", el cual busca dirimir de manera amigable un conflicto surgido con motivo de la interpretación o aplicación de la Ley para que las partes lleguen a un acuerdo o convenio. En caso de no lograrlo, se someten al arbitraje según las reglas del capítulo III de la Ley y de aplicación supletoria el Código de Comercio, cuyo resultado es un laudo definitivo, inapelable y obligatorio. Este procedimiento de arbitraje se incorporó a la legislación desde que se tiene conocimiento, hace aproximadamente nueve años. 
Los mecanismos alternativos son una alternativa atractiva en virtud de lo que señala Tan (2018), parafraseando a Andrew Phang:

El factor de atracción de los procedimientos ADR se puede atribuir al simple hecho de que ofrecen algo para todos: un canal adicional para facilitar el acceso a la justicia, ofreciendo de este modo un desahogo administrativo a los tribunales y a los organismos públicos; una vía potencialmente rápida, barata y flexible para las partes en litigio para solucionar controversias; así como una industria en crecimiento y un negocio crecientemente rentable para los profesionales y las instituciones relacionadas con estos mecanismos (Tan, 2018, p. 10).

Estas son algunas de las razones por las cuales utilizar estos procedimientos alternativos con los que coinciden la OMPI y Tan: son únicos, por lo que existe neutralidad; las partes tienen autonomía en relación con el idioma y el procedimiento; existe confidencialidad; las resoluciones o laudos (en el arbitraje) son irrevocables y tienen fuerza ejecutiva; los decisores son especialistas en temas de propiedad intelectual y elegibles por las partes. Asimismo, el procedimiento presenta celeridad y menor costo (Organización Mundial de la Propiedad Intelectual, s.f.-c).

En relación con las ventajas de la utilización de los MASC en materia de propiedad intelectual, según Tan (2018), estos permiten de cierta manera personalizar el procedimiento: se pueden elegir a las autoridades o expertos que resuelven de la lista con la que cuenta la OMPI, lo que no sucede en los tribunales, donde el juez o magistrado que resuelve no es elegible; los expertos están altamente especializados en la materia -aunque también en los tribunales se cuenta con especialización-; estos unifican la solución a los conflictos si las partes residen en distintos países porque se les aplica una sola legislación, lo que a su vez reduce el costo y tiempo invertido; tienen la característica de ser sencillos, ya que se desarrollan en pocas etapas procesales -lo que no pasa en un litigio en los tribunales-, que son más cortas (el elemento del tiempo es relevante por la vigencia de los derechos de propiedad intelectual, que es limitada según disponga la 
legislación); ${ }^{2}$ existe confidencialidad en relación con el procedimiento y la resolución, que puede ser público o no, lo que impacta, por ejemplo, en materia de secretos industriales o comerciales en los que es indispensable la confidencialidad (Tan, 2018, pp. 14-22).

En relación con las resoluciones, con motivo de la utilización de los métodos alternativos, pueden ser vinculantes (sinónimo de "obligatorias") o no, revocables (sinónimo de "anulable") e irrevocables, dependiendo del mecanismo alternativo utilizado. Por supuesto que la posibilidad de impugnación o revocación también depende de las disposiciones de la legislación y del tiempo que esta señale para hacerla efectiva, así como de los acuerdos previos que las partes hayan celebrado.

Cuando se trata de la mediación y la conciliación, las resoluciones no son vinculantes, esto se debe también a que son dos métodos autocompositivos de solución de conflictos que permiten una resolución amigable del conflicto (Escartín Escudé, 2012, pp. 106-207), pero en el arbitraje sí es vinculante. Por otra parte, en el caso de la decisión de experto, esta puede ser vinculante o no, según decidan las partes.

Se dice que en los procedimientos alternativos existe un acercamiento o acuerdo amigable entre las partes, lo que no sucede en los tribunales ni en el arbitraje, que, pese a ser este último un mecanismo alternativo, es de carácter heterocompositivo.

El mediador no puede imponer una decisión. El acuerdo de las partes tiene el efecto de un contrato [...] La mediación deja abier-

2 Los nombres de dominio impactan en figuras como: marcas y avisos comerciales, los cuales tienen una vigencia de 10 años a partir de su otorgamiento; las denominaciones de origen, que subsisten en tanto se mantengan las condiciones que les dieron origen y los efectos de la autorización para su utilización tienen una vigencia de 10 años. Por su parte, las reservas de derechos al uso exclusivo, de acuerdo con su naturaleza en géneros (es decir, si se trata de publicaciones y difusiones periódicas, personajes de caracterización o ficticios, personas o grupo dedicados a actividades artísticas y promociones publicitarias, acorde con el artículo 173 de la Ley Federal del Derecho de Autor), pueden tener una vigencia de un año en títulos de publicaciones o difusiones periódicas y de cinco años en los otros casos. 
ta la posibilidad de someterse posteriormente a un procedimiento judicial o a un arbitraje [...] Como alternativa privada, el arbitraje normalmente excluye opciones judiciales. (Centro de Arbitraje y Mediación de la OMPI, 2016, p. 6)

Asimismo, son revocables, es decir, se pueden impugnar la mediación, la conciliación y la decisión de experto (salvo que las partes o la reglamentación señalen otra cosa), pero es "irrevocable el arbitraje". 3

En relación con lo anterior, Tan, al citar al autor S. I. Strong, señala que los procedimientos de ADR de carácter internacional "son adecuados para las controversias transfronterizas [...] el arbitraje internacional ha resultado especialmente atractivo por su carácter definitivo y por la relativa facilidad para ejecutarlo internacionalmente" (Tan, 2018, p. 12).

Es de suma importancia que las resoluciones tengan una ejecución por las autoridades nacionales e internacionales, sin ello, no tendría mucho sentido o grandes ventajas el acudir a una vía alternativa, que no podría ser aplicada o ejecutada para solucionar conflictos en materia de propiedad intelectual y obtener beneficios de una resolución favorable.

Si bien existen varios mecanismos alternativos, en el ámbito internacional es la decisión de experto el más utilizado para la solución de conflictos por ciberocupación. Opinan Pampillo Balińo et al. (2012):

Aunque parezca una solución poco vinculante, la realidad es que dado el carácter de conflicto entre particulares que este tipo de controversias tipifican desde un punto de vista legal, la realidad es que justamente por tener una solución por parte de un panel de expertos y por la facilidad de ejecución sin más instancias que atrasen el

3 Se denomina "laudo" a la resolución que surge con motivo de un arbitraje. No es apelable, sino definitivo, y es ejecutado en virtud de la fuerza otorgada por la Convención de Nueva York, también llamada Convención sobre el reconocimiento y ejecución de las sentencias arbitrales extranjeras, a través de la cual los Estados miembros tienen la obligación de reconocerlo, sin revisar el fondo. 
cumplimiento del fallo de los panelistas en materia de controversias entre marcas y dominios ha resultado efectiva [...] no solo posee en su resoluciones y etapas procesales un lenguaje más transparente y claro, sino que puede entrar al fondo del problema reconocerle un carácter de signo distintivo [...] al nombre de dominio sin que esto pueda invalidar el fallo. (p. 287)

\subsection{Normas jurídicas aplicables}

La revisión de la legislación constituye un parámetro elemental para determinar el alcance de la promoción, protección y defensa de la propiedad industrial, que deriva de normas internacionales, constitucionales y nacionales de distintos tipos. En el caso mexicano, en la vía administrativa alternativa, en la solución a los conflictos por nombres de dominio .MX solo aplican las normas internacionales.

El procedimiento uniforme de resolución de disputas por nombres de dominio es un procedimiento electrónico, llevado a cabo por los expertos del Centro de Arbitraje y Mediación de la OMPI, que aplican la decisión de experto. ${ }^{4}$ Este procedimiento se rige por las siguientes normas:

1. La LDRP. Esta es una variante de la política uniforme de solución de controversias en materia de nombres de dominio (UDRP, por sus siglas), que México adaptó en relación con su nombre de dominio de nivel superior para código de país. La política no contiene el procedimiento, sino las pautas básicas sobre los derechos protegidos, controversias aplicables, tasas y resoluciones.

2. Las políticas generales de nombre de dominio .MX. Establecen

4 Es uno de los métodos alternativos de solución de controversias-además de la mediación, el arbitraje y el arbitraje acelerado-, que se utiliza para solucionar los conflictos por nombres de dominio ante uno de los proveedores de servicios de resolución de disputas, que cuenta con expertos especializados. En el caso mexicano, el único proveedor es el Centro de Arbitraje y Mediación de la OMPI, cuya resolución o decisión emitida puede ser o no vinculante para las partes, si de común acuerdo estas lo señalan, y por lo general no excluye la posibilidad de acudir a los tribunales. Puede ser impugnada en un término de 10 días después de emitida la decisión respectiva con motivo del inicio del procedimiento. 
las reglas para el registro de los nombres de dominio y los efectos que conlleva.

3. El reglamento de la política de solución de controversias en materia de nombres de dominio para .MX. Detalla las reglas del procedimiento, la presentación de solicitudes de resolución, la contestación, las etapas y el tiempo que toma cada una.

4. El Reglamento Adicional de la Organización Mundial de la Propiedad Intelectual relativo al reglamento de solución alternativa de controversias .MX. Señala cuestiones adicionales para la presentación de solitudes ante este proveedor.

5. El Reglamento de Decisión de Experto. Desarrolla los detalles del mecanismo alternativo y las reglas de su utilización.

\subsection{Autoridades responsables}

Las autoridades que llevan a cabo el procedimiento en la vía alternativa son los proveedores de servicios de resolución de disputas por nombres de dominio, ${ }^{5}$ acreditados ante la Corporación para la Asignación de Nombres y Números de Internet (ICANN, por sus siglas en inglés). En el caso mexicano, el único proveedor y, por lo tanto, autoridad responsable es el Centro de Arbitraje y Mediación de la OMPI, que cuenta con diversos expertos en la materia.

Junto al proveedor, la otra autoridad responsable es la entidad registradora nacional que ejecuta las resoluciones: Registry .MX, o los registradores acreditados que dependen de esta. La entidad forma parte del Network Information Center -o NIC México- (García, 2002, p. 62), que administra el código territorial .MX.

El procedimiento se inicia a través de una solicitud ante el proveedor -en los casos en que exista un conflicto por el registro o el

5 Estos proveedores, según datos de la ICANN, son: el Centro Árabe de Resolución de Disputas de Nombres de Dominio (ACDR), el Centro Asiático de Resolución de Disputas de Nombres de Dominio, el Centro Canadiense de Resolución de Disputas de Nombres de Dominio (CIIDRC), el Tribunal de Arbitraje/Centro de Arbitraje Checo para Disputas de Internet, el Foro Nacional de Arbitraje (NAF) y el Centro de Arbitraje y Mediación de la OMPI. 
uso de un nombre de dominio- ${ }^{6}$ por una posible vulneración de derechos de propiedad intelectual, ya sea del titular de una marca, de una denominación de origen, de un aviso comercial o de una reserva de derechos al uso exclusivo (esto, en materia de derechos de autor) (Registry .MX, s.f.-a, apartado 1.a), lo que se tendrá que demostrar ante el proveedor según las reglas señaladas en la normatividad aplicable, la cual se indicó en líneas anteriores.

Cuando se inicia un procedimiento con motivo de una disputa de propiedad intelectual en el que está implicado un nombre de dominio, el proveedor que lo lleva a cabo emite la resolución y se la envía a la entidad registradora para que esta haga efectiva la ejecución, coadyuvando a su cumplimiento y otorgando la cesión o la cancelación del nombre de dominio ${ }^{7}$ a quien demuestre tener un mejor derecho.

\subsection{Tasas}

Para determinar las tasas o costos que se erogan para acceder a la vía alternativa ante el proveedor de servicios, hay que tomar en cuenta las tasas administrativas que el proveedor ha establecido y los "honorarios a los expertos"8 que resuelven el conflicto, también determinados por este (Organización Mundial de la Propiedad Intelectual,

6 El apartado 1.a de la LDRP facilita la demostración de mala fe cometida por el titular del nombre de dominio en conflicto, ya que permite la opción de demostrar que "el nombre de dominio ha sido registrado o se utiliza de mala fe", pues la letra "o" representa una cuestión optativa.

7 El resultado del procedimiento alternativo puede constar en cancelar o ceder el nombre de dominio en controversia (las dos consecuencias jurídicas por las que puede optar el demandante en caso de una resolución favorable para él, la cual demuestra la ciberocupación) o, en el caso contrario, la denegación de la demanda (es decir, una resolución negativa).

8 Según el artículo 22.b del Reglamento de Decisión de Experto, se deben abonar los honorarios del experto para que este sea designado, los cuales dependen de circunstancias como: si el pago será por hora o por día, la cuantía del asunto o importes reclamados, la complejidad de la controversia u otra circunstancia, como por ejemplo el número de expertos y de nombres de dominio implicados. 
2016, artículo 21). Por lo general, quien abona las tasas es quien ha iniciado el procedimiento -el demandante- y, por excepción, pueden ser ambas partes (Corporación para la Asignación de Nombres y Números de Internet, 2012, apartado 4.g).

Se toman como base las tasas de la decisión de experto determinadas por el proveedor (Organización Mundial de la Propiedad Intelectual, s.f.-a) y se realiza la conversión de estas en función de la UN Operational Rates of Exchange de la Organización de las Naciones Unidas, cuyo precio de 1 dólar, a la fecha de consulta, es igual a 20.69 pesos mexicanos (Naciones Unidas, 2021). Esta conversión se muestra en la Tabla 1.

\begin{tabular}{|c|c|c|c|c|}
\hline & \multicolumn{2}{|c|}{ ÚNICO MIEMBRO } & \multicolumn{2}{|r|}{ TRES MIEMBROS } \\
\hline $\begin{array}{l}\text { Número de } \\
\text { nombres de } \\
\text { dominio } \\
\text { incluidos en la } \\
\text { demanda }\end{array}$ & $\begin{array}{c}\text { Tasa } \\
\text { administrativa } \\
\text { Centro de la } \\
\text { OMPI }\end{array}$ & Honorarios de expertos & $\begin{array}{c}\text { Tasa } \\
\text { administrativa } \\
\text { Centro de la } \\
\text { OMPI }\end{array}$ & Honorarios de expertos \\
\hline \multirow[t]{2}{*}{1 a 5} & $\$ 10345 \mathrm{MX}$ & $\$ 20690 M X$ & $\$ 20690 M X$ & $\begin{array}{c}\text { Presidente: } \$ 31035 \mathrm{MX} \\
\text { Grupo de expertos: } \$ 15517 \mathrm{MX}\end{array}$ \\
\hline & \multicolumn{2}{|c|}{ TOTAL \$ 31035 MX } & \multicolumn{2}{|c|}{ TOTAL \$ $82760 \mathrm{MX}$} \\
\hline \multirow{2}{*}{6 a 10} & $\$ 14483 \mathrm{MX}$ & $\$ 26897 M X$ & $\$ 25862 M X$ & $\begin{array}{c}\text { Presidente: } \$ 36207 \mathrm{MX} \\
\text { Grupo de expertos: } \$ 20690 \mathrm{MX}\end{array}$ \\
\hline & \multicolumn{2}{|c|}{ TOTAL \$ $41380 \mathrm{MX}$} & \multicolumn{2}{|c|}{ TOTAL \$ $103460 \mathrm{MX}$} \\
\hline
\end{tabular}

Tabla 1. Tasas administrativas y de honorarios de la decisión de experto en moneda mexicana para la solución alternativa de conflictos por nombres de dominio. Fuente: elaboración con base en Organización Mundial de la Propiedad Intelectual (s.f.-a) y Organización de las Naciones Unidas (2021).

Las tasas del proveedor se encuentran expresadas en dólares americanos, pero se pueden pagar también en euros, francos suizos o libras esterlinas con tarjeta de crédito o mediante transferencia a la cuenta corriente de la OMPI (Organización Mundial de la Propiedad Intelectual, s.f.-a).

En la Tabla 1, el costo de la decisión de experto -es decir, la solución alternativa- se encuentra en un rango de 1500 a 5000 dólares americanos (Organización Mundial de la Propiedad Intelectual, s.f.-a). En pesos mexicanos, el rango va de 31500 a 103460. Estas cantidades equivalen a la suma de la tasa administrativa más los honorarios de experto(s), pues ambos deben ser cubiertos. 


\subsection{Tiempo}

Para medir el tiempo en el que se obtiene una decisión o resolución a través del procedimiento alternativo de solución de conflictos por nombres de dominio .MX basta con revisar las etapas y su término, señaladas en el reglamento de la política de solución de controversias en materia de nombres de dominio para .MX.

Existen ocho etapas ordinarias y dos etapas excepcionales del procedimiento (Registry .MX, s.f.-c, artículos 4, 5, 8, 11-17, 20, 22). Cada una tiene una temporalidad específica.

En la primera etapa se presenta la solicitud y la entidad registradora bloquea el nombre de dominio, lo cual no lleva un tiempo determinado; la segunda etapa es opcional, solo se da en caso de corrección de la solicitud en un término de 5 días; la tercera etapa comienza con el pago de la tasa administrativa en un término de 7 días; la cuarta etapa es excepcional: en caso de no haberse pagado en el primer plazo, se da el plazo adicional de 7 días; la quinta etapa constituye el envío de la demanda, siempre y cuando esta no presente correcciones, en un término de 3 días; en la sexta etapa se le da al demandado un término de 20 días para que dé contestación; la séptima etapa -nombramiento del experto(s) - tiene un plazo de 5 días; la octava etapa -cierre del procedimiento-se da a los 10 días; la novena etapa -emisión de la resolución- tiene un término de 7 días, y es notificada a las partes para su ejecución; y la última etapa, la de ejecución, no tiene un tiempo especifico, sin embargo, si bien no se señala en el reglamento de la política de solución de controversias en materia de nombres de dominio para .MX ni en la LDRP, se podría establecer el término de 10 días acorde con la UDRP (Corporación para la Asignación de Nombres y Números de Internet, 2012, apartado 4.k).

En suma, se obtiene resolución en un plazo de 52 a 64 días, es decir, de dos a tres meses, lo que se puede verificar revisando también las resoluciones emitidas por el Centro de Arbitraje y Mediación de la OMPI. Este tiempo dependerá en todo caso de que no se den plazos adicionales o etapas excepcionales, y a los días señalados habrá que sumarles los 10 días de la ejecución, que no están expresamente señalados en el reglamento mencionado.

La celeridad en la obtención de la resolución muestra por sí mis- 
ma la ventaja frente al tiempo en el que se obtiene una resolución en la vía contenciosa, lo que se analizará más adelante.

\subsection{Resultado o resolución}

Hablar del logro del resultado es mostrar la eficacia de la vía alternativa, o sea, si se somete el caso a una solución y de ello se obtiene una resolución favorable, por lo tanto, el conflicto es resuelto y se da así la cesión del nombre de dominio en controversia a quien haya demostrado tener un mejor derecho.

En México, en el período 2001-2021, como país demandante se han presentado un total de 440 casos; y como país demandado, un total de 620 casos (Organización Mundial de la Propiedad Intelectual, s.f.-d). Sin embargo, según datos del Centro de Arbitraje y Mediación de la OMPI (s.f.), solo se encuentran disponibles las resoluciones de 439 casos. En la Tabla 2 se muestra el número total de casos por dominios .MX.

\begin{tabular}{l|c|c|c|c}
\hline \multicolumn{5}{c}{$\begin{array}{c}\text { Sentido de la resolución .MX } \\
\text { Período 2001-2020 }\end{array}$} \\
\hline Resultado & Cesión & Denegación & Archivado & \multirow{2}{*}{ Cancelación } \\
\hline \multirow{2}{*}{ Casos } & \multirow{2}{*}{344} & \multirow{2}{*}{36} & \multirow{2}{*}{3} \\
\cline { 3 - 4 } & & & *Resoluciones no disponibles & \\
\hline Total de casos & \multicolumn{3}{|c}{439} & \\
\hline
\end{tabular}

Tabla 2. Sentido de la resolución en los casos de disputas por nombres de dominio .MX. Fuente: elaboración propia con base en los datos del Centro de Arbitraje y Mediación de la OMPI (s.f.).

Los datos anteriores están en constante actualización, según la fecha de consulta y la emisión de la resolución de los casos.

Es necesario recordar que la resolución de la decisión de experto puede consistir en: otorgar la cesión -caso en el cual se acredita la ciberocupación-, cancelar el nombre de dominio, denegar la demanda o mandarla al archivo (por ejemplo, cuando no se le da seguimiento o no se pagan las tasas). Sin embargo, el nombre de dominio también se puede cancelar o ceder por orden de un tribunal o mediante 
laudo, acudiendo al arbitraje (Corporación para la Asignación de Nombres y Números de Internet, 2012, apartado 3).

Por otro lado, el nombre de dominio puede ser modificado como parte de las actividades regulares que lleva a cabo la entidad registradora, ${ }^{9}$ pero sin necesidad de iniciar un procedimiento por disputas de propiedad intelectual en relación con el dominio .MX.

En suma, los números de la Tabla 2 -traducidos en porcentajesdan un aproximado de $80 \%$ correspondiente al logro del resultado, porque se ha obtenido una resolución favorable -cesión- y se ha resuelto el conflicto, dando así un alto grado de eficacia, y 20\% que no se ha llegado al logro del resultado.

En relación con la eficacia y las resoluciones derivadas del procedimiento, estas no siempre resuelven los conflictos por ciberocupación. Ello se debe a que la resolución depende de las consideraciones del experto, de la cita de otros casos, de las pruebas que ofertan las partes y de los alegatos, entre otros.

En el caso mexicano existen pocos casos, a diferencia de otros países donde existen altos números de demandas por nombres de dominio. Sin embargo, el hecho de que sean pocos los casos sometidos ante el proveedor de servicios de resolución de disputas no quiere decir que exista menor ciberocupación. Se debe considerar el hecho de que el tiempo y el costo invertidos para la defensa legal es lo que genera una reducción de casos resueltos por la vía legal y el aumento del aprovechamiento de los "ciberocupas", quienes tienen mayor experiencia para la vulneración de derechos de terceros.

Para terminar, la resolución dada con motivo del procedimiento tiene una serie de requisitos que coinciden con los de las resoluciones que emiten los tribunales, como constar por escrito, describir la controversia, las razones o hechos (fundamentación y motivación en las resoluciones de los tribunales), fecha y firma del experto (Organización Mundial de la Propiedad Intelectual, 2016, artículo 17).

9 La entidad registradora también puede realizar registros de nombre de dominio, renovarlo, eliminarlo, transferirlo, restaurarlo como parte de sus actividades normales y bloquearlo cuando existe un procedimiento iniciado por disputas sobre este. 


\section{Eficiencia y eficacia de la vía contencioso-administrativa o extrajurisdiccional}

A manera de antecedente, un hecho particularmente importante en México fue la inclusión de una infracción administrativa en la legislación por el uso de nombres de dominio como marcas. Antes de noviembre de 2020, el uso de un nombre de dominio similar o igual a una marca registrada no constituía una infracción administrativa explícitamente regulada en la legislación.

Con la firma y entrada en vigor del Tratado entre los Estados Unidos Mexicanos, Estados Unidos de América y Canadá (el T-MEC), México adquirió diversas obligaciones, que se concretaron en varias reformas en materia de propiedad intelectual, así como la publicación de la Ley Federal de Protección a la Propiedad Industrial, que abrogó la Ley de la Propiedad Industrial en el año 2020. Con lo anterior, en lo que respecta a los nombres de dominio, se adquirió la obligación de incluir un procedimiento para solucionar las controversias por nombres de dominio .MX, con las características de ser expedito, a bajo costo, justo y equitativo, sencillo y que permita recurrir a los tribunales, así como contar con una base de datos para la consulta de nombres de dominio (Diario Oficial de la Federación, 2020, p. 449).

Sin embargo, en México ya se contaba con un procedimiento alternativo para solucionar conflictos por nombres de dominio -basado en la UDRP-, denominado LDRP, en el que participan la entidad registradora, Registry.MX, y el proveedor de servicios de resolución de disputas, el Centro de Arbitraje y Mediación de la OMPI.

En lo relativo a la Ley Federal de Protección a la Propiedad Industrial, cuya aplicación administrativa le corresponde al IMPI, contempla, entre otras cosas, medidas administrativas y jurisdiccionales para la protección de la propiedad industrial. La Ley entró en vigor el 5 de noviembre de 2020, y en su artículo 386 señala los supuestos para la determinación de las infracciones administrativas. Particularmente en las fracciones XVIII y XX del artículo mencionado señala:

Artículo 386.- Son infracciones administrativas:

$[\ldots]$ 
XVIII.- Usar, sin consentimiento de su titular, una marca registrada o semejante en grado de confusión como elemento de [...] un nombre de dominio o viceversa [...]

XX.- Usar una marca previamente registrada o semejante en grado de confusión como [...] nombre de dominio o como partes de éstos, de una persona física o moral cuya actividad sea la producción, importación o comercialización de bienes o servicios iguales o similares a los que se aplica la marca registrada, sin el consentimiento, manifestado por escrito, del titular del registro de marca o de la persona que tenga facultades para ello. (Diario Oficial de la Federación, Ley Federal de Protección a la Propiedad Industrial, 2020) ${ }^{10}$

Los supuestos citados claramente señalan que solo se pueden hacer efectivos cuando existe un conflicto entre una marca registrada y el uso de un nombre de dominio. Esto es sumamente importante, ya que con ello se quiere decir que solo permite probar el uso ${ }^{11}$ del nombre de dominio, no así el registro, o al menos eso se interpreta de la literalidad de la legislación, pese a que, conforme con los criterios establecidos en la LDRP, se puede acreditar el "uso o el registro" (optativamente) de un dominio (Registry.MX, s.f.-a, apartado 1.a). Lo anterior también muestra una exclusión para los titulares de una denominación de origen, aviso comercial o reserva de derechos al uso exclusivo, lo que sí permite la LDRP.

No estaría de más que la cuestión del uso o el registro se plasme en la legislación, porque haría más sencilla la carga probatoria para el reclamante y tendría mayor oportunidad de demostrar la mala

10 Énfasis agregado.

11 La Ley Federal de Protección a la Propiedad Industrial, en su artículo 387, aclara que lo que se entenderá por "usar" es enunciativo, mas no limitativo, y se refiere a: "fabricar, producir, imitar, almacenar, distribuir, importar, exportar, ofrecer en venta, vender, transportar o poner en circulación”. Se considera que la palabra "registro" no se estableció como parte de la redacción de la infracción, porque la autoridad competente en la materia no es el IMPI, sino la ICANN. Aunado al hecho de que no hay certeza de en qué grado afecta a los derechos marcarios el solo registro del nombre de dominio, lo que es complejo demostrar en la vía legal, aunque queda claro que es mucho más sencillo acreditar el registro que el uso, y este último es más evidente. 
fe, y porque registrar también es una vulneración a los derechos del titular de una marca cuando ese registro es idéntico o semejante en grado de confusión al de la marca y se realiza de mala fe, así como incluir la colisión de derechos entre el nombre de dominio y los otros derechos de propiedad intelectual señalados acorde a las normas vigentes de la LDRP.

La inclusión de la infracción administrativa marca-nombre de dominio permite iniciar en primera instancia un procedimiento de declaración administrativa de infracción, cuya autoridad responsable es el IMPI. Es una condición obligatoria agotar esta instancia para poder acceder a la vía contencioso-administrativa, es decir, al juicio contencioso-administrativo ante el Tribunal Federal de Justicia Administrativa, lo que se analizará más adelante. Además, como ya se ha señalado, se puede acudir a resolver el conflicto a través de los mecanismos alternativos de solución de controversias que permite la legislación mexicana, como conciliación o arbitraje, o los que ofrece el Centro de Arbitraje y Mediación de la OMPI.

Cabe señalar, aunque resulte muy lógico jurídicamente, que no pueden existir dos procedimientos a la vez, pero una vez terminado uno, nada impide acudir a otro, ya sea un procedimiento administrativo, contencioso o uno alternativo.

Es importante no omitir el procedimiento de declaración administrativa de infracción, porque a partir de ahí, si fuera el caso, se obtendrá una resolución que, de ser negativa, permitirá acudir a la vía contenciosa. En este artículo, la vía administrativa previa no es analizada, pues podría darse el caso de que se obtenga una resolución favorable en esta vía, lo que no permitiría hacer una comparación de las vías alternativa y contencioso-administrativa, objetivo de este análisis.

\subsection{Normas jurídicas aplicables}

En la vía contencioso-administrativa, la principal norma aplicable es la Ley Federal de Procedimiento Contencioso Administrativo (LFP$\mathrm{CA}$ ), la cual establece todas las reglas procesales para la presentación de demandas mediante juicio, los plazos y las pruebas, entre otras cosas.

En cuanto al fondo del asunto, toda resolución impugnada mediante juicio debe estar fundada en la Ley Federal de Protección a 
la Propiedad Industrial u otra ley de propiedad intelectual, de ser el caso.

El juicio contencioso-administrativo puede ser tramitado en forma tradicional o a través del sistema de juicio en línea, que fue implementado hace unos diez años y el cual sigue las mismas etapas del trámite tradicional, pero sin acudir presencialmente al tribunal. Este juicio también puede tener la característica de ser ordinario o sumario.

La vía sumaria no es procedente en este caso en virtud de lo que establece el artículo 58-3 de la LFPCA: "Es improcedente cuando se trata de multas por infracciones a las normas en materia de propiedad intelectual". Lo anterior, debido a que el uso del nombre de dominio en relación con la marca constituye una infracción que, de ser demostrada, traerá consigo una sanción, es decir, la posibilidad de una multa, por ello no puede tramitarse el juicio contencioso en la vía sumaria.

\subsection{Autoridad responsable}

La autoridad que lleva a cabo el juicio contencioso-administrativo es el Tribunal Federal de Justicia Administrativa (TFJA), a través de su Sala Regional Especializada en materia de Propiedad Intelectual. Este tribunal es un órgano constitucional autónomo, ya que no depende orgánicamente de ninguno de los poderes ordinarios, especialmente no forma parte del Poder Judicial de la Federación (como puede suceder en algunos tribunales en otros países). La designación de los magistrados que lo integran se realiza a propuesta del Ejecutivo Federal con ratificación de las 2/3 partes del Senado según el artículo 73, fracción XXIX-H de la Constitución Política de los Estados Unidos Mexicanos.

Su integración está prevista en la Ley Orgánica del Tribunal Federal de Justicia Administrativa, constituido por la Sala Superior, la Junta de Gobierno y Administración y las Salas Regionales (artículo 6). A su vez, las salas regionales son de cuatro tipos: Ordinarias, Auxiliares, Especializadas ${ }^{12}$ y Mixtas (artículo 28).

12 Las salas regionales están especializadas en materia de: propiedad intelectual, juicios en línea, ambiental y de regulación, comercio exterior (con 3 salas), 
La Sala Regional Especializada en materia de Propiedad Intelectual competente para llevar a cabo el juicio contencioso fue creada en 2008 y tiene su sede en la Ciudad de México (Diario Oficial de la Federación, 2008), e inició sus funciones en el año 2009, atendiendo juicios tramitados en forma tradicional y juicios en línea.

La aparición de las Salas Especializadas del TFJFA responde, en principio, a la diversidad de la materia administrativa, que obliga la presencia de juzgadores dedicados exclusivamente a resolver controversias en ciertos rubros administrativos que han alcanzado complejidad (como fue la creación de la Sala Regional en Materia de Propiedad Intelectual, en marzo de 2008) [...] La especialidad de los órganos jurisdiccionales resulta un imperativo para atender las necesidades sociales de justicia de la sociedad mexicana. (Pérez, 2012, pp. 27-28)

La Sala Especializada en comentario, con arreglo a la Ley Orgánica del Tribunal Federal de Justicia Administrativa, artículo 3, fracciones I, IV, XII, XIII, XV y último párrafo, tiene competencia para conocer todos aquellos juicios promovidos en contra de resoluciones definitivas, actos y procedimientos administrativos con fundamento en las leyes de propiedad intelectual, como las resoluciones dictadas por las autoridades administrativas (como el IMPI), que pongan fin a un procedimiento administrativo, a una instancia o resuelvan un expediente, y las que decidan los recursos administrativos en contra de las resoluciones. Esto, además, se reitera en el artículo 407 de la Ley Federal de Protección a la Propiedad Industrial.

\subsection{Tiempo y costo}

Como fue mencionado con anterioridad, existen dos parámetros para medir la eficiencia: el tiempo de obtención de una resolución y el costo de la solución al conflicto. Esta eficiencia, entonces, consiste

juicio de resolución exclusiva de fondo y de responsabilidades administrativas (con 5 salas). Todas sus facultades se encuentran en el artículo 50 del Reglamento Interior del Tribunal Federal de Justicia Administrativa. 
en lograr el resultado en el menor tiempo y con la menor cantidad de recursos posibles.

Para establecer una medición del tiempo en el que se obtiene una resolución en el juicio contencioso-administrativo, comparado con la vía alternativa, se debe revisar la LFPCA, que prevé las etapas y el tiempo que insume cada una (artículos 13, fracciones I, II y III, 17, 19, 25, 47 y 49). Empero, en algunas etapas del juicio no se especifican los plazos en la legislación. Estas etapas son:

1. Presentación de la demanda: se tiene un plazo de 30 días contados a partir de que surta efecto la notificación de la resolución que se impugna (por excepción, 5 años cuando las autoridades demanden la modificación o nulidad de una resolución favorable para el particular). La demanda se puede ampliar en los casos excepcionales por el término de 10 días.

1.1. Solicitud de medidas cautelares: es opcional; si se presenta la solicitud, se tiene un día para emitir el acuerdo que admita el incidente de petición de las medidas, se corre traslado a quien se le imputa el acto y este debe emitir un informe dentro de los 3 días. A los 5 días de presentado el informe, se da la resolución sobre la concesión o la negativa de las medidas.

2. Contestación de la demanda: cuenta con un plazo de 30 días. Si existe ampliación de la demanda, se otorgan 10 días contados a partir de que surta efecto la notificación del acuerdo que admita la ampliación.

3. Período probatorio: la LFPCA no indica un plazo específico, por lo que este se puede ampliar tanto como lo decidan los magistrados del tribunal o la carga de trabajo.

4. Cierre de la instrucción: concluida la sustanciación del juicio y el período probatorio, se cuenta con 5 días para presentar alegatos.

5. Sentencia: se debe emitir dentro de los 45 días contados a partir de que haya quedado cerrada la instrucción en el juicio.

En resumen, de las etapas antes descritas de la vía contenciosoadministrativa, y con respecto al ideal de justicia pronta y expedita -que puede distar de la realidad-, se debería obtener una resolución aproximadamente entre los 140 a 160 días (en el supuesto de 30 días, de período probatorio), es decir, de cinco a seis meses. Sin embargo, no se está considerando el tiempo que tarda el IMPI en 
resolver la solicitud de declaración de infracción administrativa en la vía administrativa, que es previa y obligatoria para el trámite del juicio contencioso-administrativo, término que puede ser de aproximadamente tres meses, conforme a la Ley Federal de Procedimiento Administrativo. ${ }^{13}$

En otro orden de ideas, la propiedad intelectual -por su especialización- es costosa. No solo por la preparación profesional de toda aquella persona vinculada a la propiedad intelectual, sino también para aquellos titulares que invierten en la creación, registro, renovación y defensa de sus derechos ante las autoridades correspondientes. Algunos de estos gastos incluyen, por ejemplo, los que se erogan por la creación o materialización de sus ideas en creaciones industriales - por ejemplo, modelos de utilidad, patentes u otros-; por el registro de signos distintivos y creaciones industriales ante el IMPI; el costo de mantener vigentes los derechos de propiedad intelectual registrados, es decir, las renovaciones; y en caso de conflictos por infracciones a sus derechos, el costo que tiene su protección y defensa, lo que incluye el pago de honorarios de abogados, asesores, árbitros y demás especialistas.

Algunos teóricos opinan que acudir a los tribunales representa un costo más alto que acudir a la vía alternativa por tratarse de conflictos en materia de propiedad intelectual, sin embargo, ninguno ha determinado con exactitud un costo, sino aproximaciones por su variabilidad. Por ello, el parámetro de costo constituye una cuestión bastante difícil de determinar.

Los pleitos en materia de propiedad intelectual pueden ser onerosos, especialmente si conllevan recursos y litigios en el extranjero. El costo prohibitivo de los litigios en algunos países puede dificultar que las personas o las pequeñas empresas hagan valer sus dere-

13 De acuerdo con el artículo 17 de la Ley Federal de Procedimiento Administrativo, "salvo que en otra disposición legal o administrativa de carácter general se establezca otro plazo, no podrá exceder de tres meses el tiempo para que la dependencia u organismo descentralizado resuelva lo que corresponda. Transcurrido el plazo aplicable, se entenderán las resoluciones en sentido negativo al promovente, a menos que en otra disposición legal o administrativa de carácter general se prevea lo contrario". 
chos o puedan defenderse cuando se trata de demandas en materia de propiedad intelectual presentadas contra entidades de mayor tamaño o viceversa.

En comparación con los litigios judiciales, los procedimientos $\mathrm{ADR}$ ofrecen a las partes una vía asequible y accesible para solucionar sus controversias. (Tan, 2018, p. 18)

Cuando se habla de "costo" no se hace referencia al costo que tiene acceder a la justica, sino a la defensa de la propiedad industrial, pues de acuerdo con la Constitución Política de los Estados Unidos Mexicanos, el acceso a la justicia es gratuito.

Toda persona tiene derecho a que se le administre justicia por tribunales que estarán expeditos para impartirla en los plazos y términos que fijen las leyes, emitiendo sus resoluciones de manera pronta, completa e imparcial. Su servicio será gratuito, quedando, en consecuencia, prohibidas las costas judiciales. (Artículo 17, segundo párrafo)

Los pagos o tasas por los servicios que presta el IMPI (Diario Oficial de la Federación, 2021) están determinados y varían dependiendo de la figura que se desee proteger y el fin de la solicitud. A estos costos se les deben sumar los gastos erogados por la defensa de la propiedad industrial, en caso de infracciones, lo cual no es determinable, ya que depende del costo determinado por cada abogado, especialista o despacho jurídico que la lleve a cabo.

En conclusión, el costo en la vía contenciosa es no determinable o variable, a diferencia del costo en la vía alternativa, que sí es determinable y variable solo en función del valor del dólar según las tasas del proveedor de servicios de resolución de disputas.

\subsection{Resultado o resolución}

Respecto al logro del resultado o la eficacia del juicio contencioso-administrativo para resolver los conflictos entre marcas y nombres de dominio .MX, al igual que con la vía alternativa, se llega al resultado cuando se emite una resolución favorable y se resuelve el 
conflicto o, en caso contrario, cuando no se logra el resultado y se emite una resolución negativa.

En relación con el número de casos presentados en la vía contenciosa resueltos por la Sala Regional Especializada del TFJA, aún es imposible realizar una cuantificación. Ello, en virtud de que apenas en noviembre de 2020 entró en vigor la Ley Federal de Protección a la Propiedad Industrial, que contempla la infracción administrativa marca-nombre de dominio. Considerando el tiempo que tarda la obtención de una resolución (un mínimo de nueve meses), aún no se podrían demostrar los resultados de esta.

Si bien antes de la reforma los casos se presentaban en un juico contencioso alegando actos de competencia desleal, son contados los casos en los que ha estado implicado un nombre de dominio .MX y el fondo del asunto haya versado meramente sobre este y no otras cuestiones. Además, los resultados no han sido de suma relevancia y muy pocos han resultado favorables. ${ }^{14}$

Los efectos de las resoluciones en la vía contencioso-administrativa pueden consistir en reconocer la validez de la resolución impugnada (esto quiere decir que la resolución es negativa, porque reconoce que, tal cual la determinó el IMPI, no se demuestra la infracción administrativa y por ello no se logra el resultado) o declarar su nulidad (en este caso, la resolución es positiva; con ello se declara que la resolución del IMPI no tiene valor legal y se deberá emitir una nueva, con lo cual sí se llega al resultado).

En los últimos meses, la Sala Regional Especializada en materia de Propiedad Intelectual ha emitido bastantes resoluciones en las que está involucrado de alguna manera un nombre de dominio

14 De la revisión de algunas sentencias que se encuentran publicadas en el portal del Tribunal Federal de Justicia Administrativa, existen algunos juicios resueltos en los que está implicado un nombre de dominio .MX; por ejemplo, en los expedientes 1288/17-EPI-01-1, 1669/17-EPI-01-5, 1175/17-EPI-015, 370/18-EPI-01-12, 54/18-EPI-01-12, 480/18-EPI-01-9 y 667/19-EPI01-12, sin embargo, el Tribunal no se ha pronunciado favorablemente en estos casos. En el caso del expediente 45/18-EPI-01-5 sí se ha obtenido una resolución favorable, pero sin resultados relevantes. Disponibles en el sistema de consulta de sentencias públicas: http://sentencias.tffa.gob.mx:8080/ SICSEJLDOC/faces/content/public/consultasentencia.xhtml. 
.MX, sin embargo, la evolución de los casos de ciberocupación aún no es clara. Por ello, se recomienda estar pendiente de las resoluciones para demostrar con serias bases qué tan eficiente y eficaz es esta vía contenciosa.

No se debe olvidar que la vía contenciosa solo permite defender los derechos de los titulares de las marcas ante el abuso con el uso de nombre de dominio, pero no se lo permite a los titulares de avisos comerciales, denominaciones de origen y reservas de derechos al uso exclusivo, a juzgar por el fundamento del artículo 386, fracciones XVIII y XX de la Ley Federal de Protección a la Propiedad Industrial.

Finalmente, en la Tabla 3 se muestran algunas características para la ponderación de la eficacia y eficiencia de las vías estudiadas y, con ello, la determinación de las ventajas y desventajas que posee cada una.

\begin{tabular}{l|l|l|l}
\hline Característica & $\begin{array}{l}\text { Vía contencioso- } \\
\text { administrativa }\end{array}$ & $\begin{array}{c}\text { Vía alternativa } \\
\text { Decisión de } \\
\text { experto }\end{array}$ & \multicolumn{1}{|c}{ Ventaja o desventaja } \\
\hline $\begin{array}{l}\text { 1. Forma de } \\
\text { trámite }\end{array}$ & $\begin{array}{l}\text { Online/electróni- } \\
\text { co o presencial/ } \\
\text { ordinario. }\end{array}$ & $\begin{array}{l}\text { Online / elec- } \\
\text { trónico. }\end{array}$ & $\begin{array}{l}\text { La vía contenciosa tiene la ventaja, } \\
\text { ya que permite dos opciones de tra- } \\
\text { mitación, pues el trámite electrónico } \\
\text { genera desconfianza para algunos } \\
\text { usuarios y confianza para otros. } \\
\text { Ambas tienen ventaja, pues al re- } \\
\text { alizarse el trámite electrónico se le } \\
\text { da celeridad al procedimiento. }\end{array}$ \\
\hline $\begin{array}{l}\text { 2. Acceso a la } \\
\text { justicia }\end{array}$ & Gratuita. & Onerosa. & $\begin{array}{l}\text { La vía contenciosa muestra la venta- } \\
\text { ja por no tener costo, por lo que la } \\
\text { desventaja la tiene la vía alternativa. }\end{array}$ \\
\hline $\begin{array}{l}\text { 3. Su costo } \\
\text { depende de }\end{array}$ & $\begin{array}{l}\text { La cuantía en dis- } \\
\text { puta y el número } \\
\text { de abogados } \\
\text { especializados. }\end{array}$ & $\begin{array}{l}\text { Número de } \\
\text { expertos y núme- } \\
\text { ro de dominios } \\
\text { implicados. }\end{array}$ & $\begin{array}{l}\text { La desventaja la tiene la vía con- } \\
\text { tencioso-administrativa porque las } \\
\text { cuantías aumentan el costo de la } \\
\text { defensa y son pocos los abogados } \\
\text { especializados. La ventaja la tiene } \\
\text { la vía alternativa, porque existe una } \\
\text { lista de expertos más amplia y la } \\
\text { diferencia del costo por varios do- } \\
\text { minios no es tan grande. }\end{array}$ \\
\hline
\end{tabular}




\begin{tabular}{|c|c|c|c|}
\hline $\begin{array}{l}\text { 4. Costo de la } \\
\text { defensa }\end{array}$ & $\begin{array}{l}\text { Cuantía no deter- } \\
\text { minable o vari- } \\
\text { able, en virtud } \\
\text { de que requiere } \\
\text { acudir a una vía } \\
\text { previa la cual } \\
\text { tiene un costo, } \\
\text { más los honorari- } \\
\text { os del abogado } \\
\text { o experto, que } \\
\text { varían según el } \\
\text { caso. }\end{array}$ & $\begin{array}{l}\text { Cuantía deter- } \\
\text { minable, de un } \\
\text { rango de } 31035 \\
\text { a } 103450 \text { pesos } \\
\text { mexicanos. }\end{array}$ & $\begin{array}{l}\text { La ventaja es para la vía alternativa, } \\
\text { que desde un inicio establece los } \\
\text { costos totales. La desventaja la tiene } \\
\text { la vía contenciosa por la variabilidad } \\
\text { del costo. }\end{array}$ \\
\hline $\begin{array}{l}\text { 5. Requiere } \\
\text { acudir a una } \\
\text { vía previa }\end{array}$ & $\begin{array}{l}\text { Sí. } \\
\text { Requiere haber } \\
\text { acudido a la vía } \\
\text { administrativa } \\
\text { ante el IMPI, que } \\
\text { fija sus propias } \\
\text { tasas más los } \\
\text { honorarios del } \\
\text { abogado. }\end{array}$ & $\begin{array}{l}\text { No. } \\
\text { Se puede acced- } \\
\text { er en cualquier } \\
\text { momento y sin } \\
\text { condiciones } \\
\text { previas. }\end{array}$ & $\begin{array}{l}\text { La ventaja es de la vía alternativa, } \\
\text { que no requiere mayor condición } \\
\text { para acceder a esta, frente a la des- } \\
\text { ventaja de la vía contenciosa, que } \\
\text { requiere acudir a una vía previa, lo } \\
\text { que retarda la solución del conflicto. }\end{array}$ \\
\hline $\begin{array}{l}\text { 6. Especializa- } \\
\text { do en }\end{array}$ & $\begin{array}{l}\text { Propiedad in- } \\
\text { telectual. }\end{array}$ & $\begin{array}{l}\text { Conflictos comer- } \\
\text { ciales por nom- } \\
\text { bres de dominio. }\end{array}$ & $\begin{array}{l}\text { Ambos tienen ventajas porque son } \\
\text { especializadas. }\end{array}$ \\
\hline $\begin{array}{l}\text { 7. Permite } \\
\text { defender } \\
\text { derechos de } \\
\text { propiedad } \\
\text { intelectual }\end{array}$ & Solo marcas. & $\begin{array}{l}\text { Marcas, avisos } \\
\text { comerciales, de- } \\
\text { nominaciones de } \\
\text { origen y reservas } \\
\text { de derechos al } \\
\text { uso exclusivo. }\end{array}$ & $\begin{array}{l}\text { La ventaja es para la vía alternativa } \\
\text { porque amplía la protección, por lo } \\
\text { tanto, la desventaja es de la vía con- } \\
\text { tenciosa, que restringe la protección } \\
\text { a solo marcas. }\end{array}$ \\
\hline $\begin{array}{l}\text { 8. Las partes } \\
\text { pueden elegir } \\
\text { a la autoridad } \\
\text { que resuelve }\end{array}$ & No. & Sí. & $\begin{array}{l}\text { La ventaja es para ambas vías, } \\
\text { porque si bien se puede elegir o no } \\
\text { a la autoridad, en ambos casos se } \\
\text { debe garantizar la imparcialidad de } \\
\text { la decisión. Sin embargo, en la vía } \\
\text { alternativa se personaliza el proced- } \\
\text { imiento. }\end{array}$ \\
\hline $\begin{array}{l}\text { 9. Territo- } \\
\text { rialidad de } \\
\text { aplicación } \\
\text { del proced- } \\
\text { imiento }\end{array}$ & Nacional. & $\begin{array}{l}\text { Nacional e inter- } \\
\text { nacional. }\end{array}$ & $\begin{array}{l}\text { La vía alternativa tiene la ventaja } \\
\text { cuando se trata de conflictos inter- } \\
\text { nacionales. } \\
\text { Ambas vías tienen ventaja cuando se } \\
\text { trata de conflictos nacionales. }\end{array}$ \\
\hline $\begin{array}{l}\text { 10. Carácter } \\
\text { del mecanis- } \\
\text { mo }\end{array}$ & $\begin{array}{l}\text { Controvertido. } \\
\text { Obligatorio: las } \\
\text { partes no pueden } \\
\text { decidir sobre su } \\
\text { cumplimiento } \\
\text { o no. }\end{array}$ & $\begin{array}{l}\text { Controvertido. } \\
\text { Obligatorio, } \\
\text { "salvo" (es decir, } \\
\text { como excepción) } \\
\text { acuerdo entre } \\
\text { ambas partes de } \\
\text { que no lo sea. }\end{array}$ & $\begin{array}{l}\text { La ventaja es para la vía alternativa, } \\
\text { porque se flexibiliza el cumplimien- } \\
\text { to de la decisión a condición del } \\
\text { acuerdo entre las partes, que es lo } \\
\text { que caracteriza a los mecanismos } \\
\text { alternativos. }\end{array}$ \\
\hline
\end{tabular}




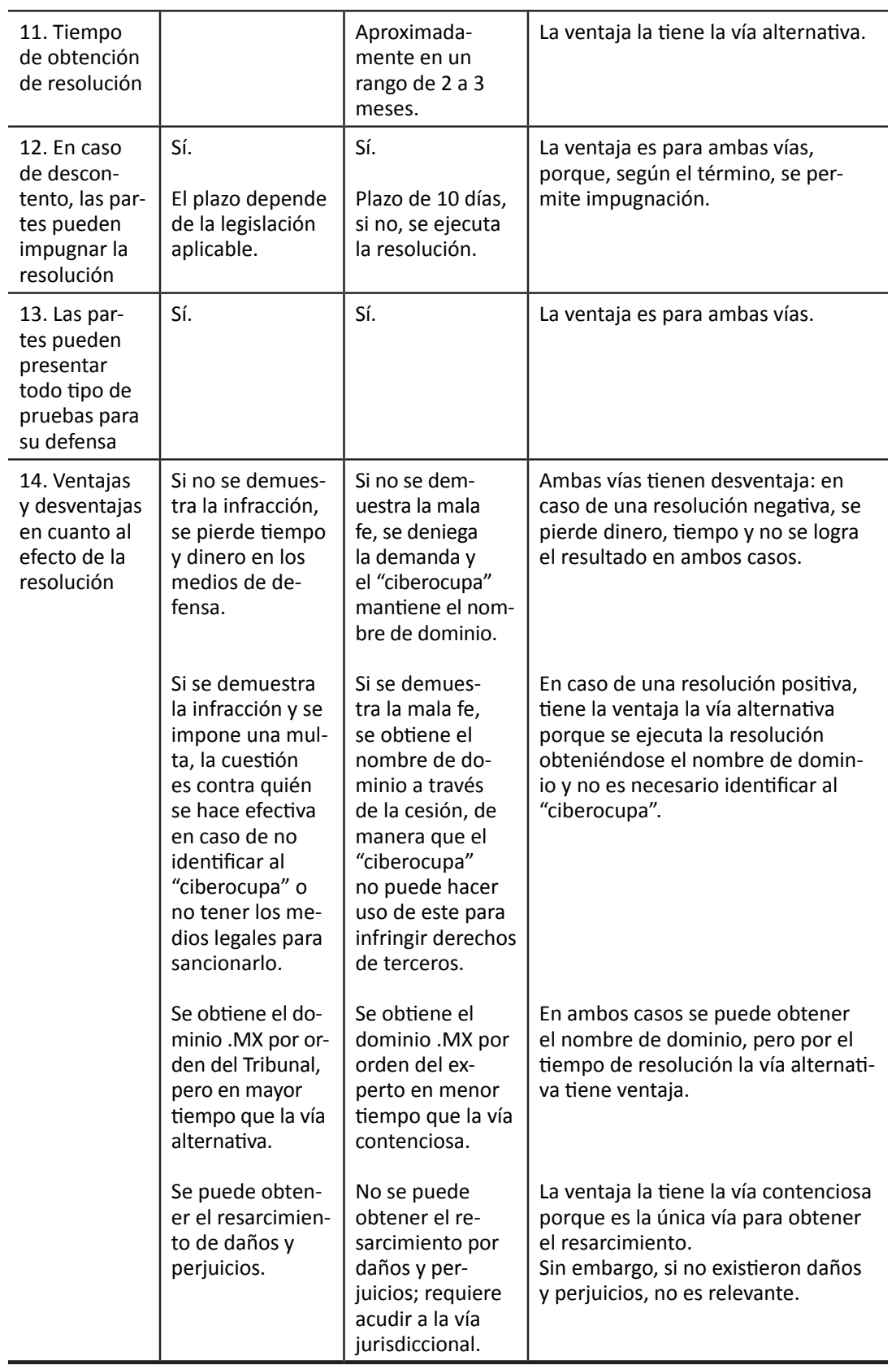

Tabla 3. Características de las vías contencioso-administrativa y administrativa alternativa para la ponderación de sus ventajas y desventajas. Fuente: elaboración propia. 
Si la ponderación se midiera en puntos de acuerdo con las características que se han descrito en la Tabla 3, la vía alternativa tendría 15 puntos frente a 9 de la vía contenciosa, lo que demuestra en qué casos la vía alternativa resulta más eficiente y eficaz. De esta manera, ambas vías son eficientes y eficaces, pero la primera en mayor grado que la segunda.

\section{Conclusiones}

En México, para que se contemplaran a los nombres de dominio como figuras que infringen los derechos de los titulares de las marcas y estos tuvieran acceso a medios de defensa ante infracciones a través del procedimiento de declaración de infracción administrativa o el juicio contencioso-administrativo, pasaron aproximadamente 29 años desde la publicación de la Ley de la Propiedad Industrial (1991) y varias reformas a esta; 27 años desde la creación del IMPI (1993); 26 años para un nuevo tratado comercial (el T-MEC); 12 años desde la creación de la Sala Regional Especializada del Tribunal Federal de Justicia Administrativa (2008); y una nueva Ley Federal de Protección a la Propiedad Industrial (2020), la cual expresamente da competencia en primera instancia al Instituto Mexicano de la Propiedad Industrial para resolver la ciberocupación de marcas, y en segunda instancia al Tribunal Federal de Justicia Administrativa.

Se ha demostrado el alto grado de eficiencia y eficacia de la vía alternativa y el grado medio de eficiencia y eficacia de la vía contencioso-administrativa para la solución de conflictos por nombres de dominio .MX gracias a los indicadores que ayudan a medirla, como el costo, el tiempo y el logro del resultado. Las dos vías tienen eficiencia y eficacia, sin embargo, una en mayor grado que la otra, si se toman en cuenta las características e indicadores determinados.

Los indicadores y características estipulados en este artículo contribuyen a orientar al titular de algún derecho de propiedad intelectual para que haga una elección razonada del medio de defensa y de la vía en materia administrativa a la que va a acudir, para así defender sus derechos y protegerse contra infracciones por el uso de nombres de dominio de mala fe, mostrando la valoración de las ventajas, desventajas, eficiencia y eficacia de las vías. Sin embargo, la 
elección dependerá del caso en concreto, del interés del titular y, al final, de su decisión sobre lo que desea obtener y del tiempo y costo que desea invertir en tener una resolución.

La eficiencia tiene dos parámetros de medición: el costo y el tiempo; la vía alternativa ha demostrado tener mayor grado de eficiencia que la vía contenciosa. Por otra parte, en cuanto a la eficacia, es decir, al logro del resultado, la vía alternativa ha demostrado tener un grado más alto que la contenciosa, esto se debe en gran medida a la falta de casos presentados y a la obtención de resoluciones negativas.

En cuanto al costo, al acudir a la vía alternativa, se tienen tasas determinadas por el proveedor de servicios de resolución de diputas, que en el caso mexicano oscila entre los 31500 y 103460 pesos mexicanos, y que solo varían de acuerdo al costo del dólar que establece la Organización de las Naciones Unidas. Por su parte, el costo de la vía contenciosa es variable. Aunque el acceso a la justicia es gratuito, la defensa de los derechos no lo es y depende de varias circunstancias, por ejemplo, de los honorarios de los especialistas y del tiempo de resolución: a mayor tiempo, mayor costo.

En cuanto al tiempo, en concordancia con las etapas del procedimiento, en la vía alternativa se obtiene una resolución en un mínimo de dos meses y máximo de tres meses frente a la vía contenciosa, en la cual se obtiene una resolución en un mínimo de cinco a seis meses, a condición de agotar la instancia previa obligatoria de mínimo tres meses, que se deben sumar al tiempo señalado. Además, no hay que perder de vista que en la vía contenciosa la obtención de resoluciones no siempre es pronta y expedita, y solo existe una Sala Regional Especializada en materia de Propiedad Intelectual que resuelve en toda la República mexicana.

En cuanto al resultado, es decir, la obtención de una resolución favorable, en la vía alternativa existen más casos y resoluciones que ayudan a realizar una medición, por ello, esta vía resulta más eficaz. En cambio, en la vía jurisdiccional aún no se han presentado tantos casos, y los pocos que hay han resultado en resoluciones negativas. Esto se debe en gran medida a que la legislación mexicana permitió acudir a la defensa de los derechos en la vía administrativa y contencioso-administrativa apenas en noviembre de 2020.

En unos ańos, con el aumento de casos se podrá determinar el grado de eficacia de la vía contenciosa y se dará respuesta a qué pasa 
más allá de la infracción administrativa marcas-nombres de dominio en México. El reconocimiento en la ley es un gran avance, producto de las obligaciones adquiridas con la entrada en vigor del T-MEC.

La incorporación de los mecanismos alternativos de solución de controversias en las legislaciones de propiedad intelectual en México ha ampliado la oportunidad de resolución de los conflictos en la materia de manera eficiente y eficaz, perfeccionando los medios de defensa tradicionales en los casos en los que existe controversia entre las partes y se permite resolver de manera alternativa.

Los mecanismos alternativos son una opción sumamente viable para la solución de conflictos en materia de propiedad intelectual, especialmente cuando se trata de conflictos por nombres de dominio y marcas, además de que estos amplían la protección y defensa de los derechos a los titulares de denominaciones de origen, avisos comerciales y reservas de derechos al uso exclusivo, lo que no está señalado en la legislación mexicana. La legislación nacional necesita adecuarse para estar acorde con los parámetros internacionales de la Política de solución de controversias en materia de nombres de dominio para .MX, de manera que no se restrinja la protección a los derechos de terceros que pueden entrar en colisión con nombres de dominio.

Entre las ventajas de la vía alternativa están: permite un acercamiento entre las partes y estas pueden elegir a la autoridad que resuelve; garantiza la transferencia del nombre de dominio en menor tiempo, gracias a la relación que existe entre el proveedor que administra el procedimiento, los expertos que lo llevan a cabo y la entidad registradora que ejecuta la resolución; las tasas están claramente determinadas; su aplicación incluye conflictos nacionales e internacionales; y no requiere acudir a instancias previas.

\section{Bibliografía}

Centro de Arbitraje y Mediación de la OMPI. (2016). Resolución de controversias de propiedad intelectual y tecnología a través de los métodos ADR de la OMPI. https://www.wipo.int/edocs/pubdocs/es/wipo_pub_799_2016.pdf.

Centro de Arbitraje y Mediación de la OMPI. (s.f.). Resoluciones rendidas por la OMPI de acuerdo a la Politica uniforme relativas a nombres de dominio (ccTLD). Recuperado el 1 de marzo de 2021 de https://www.wipo.int/amc/es/domains/ decisionsx/index-cctld2.html. 
Corporación para la Asignación de Nombres y Números de Internet. (s.f.). Lista de Proveedores de Servicio de Resolución de Disputas Aprobados. https://www. icann.org/resources/pages/providers-2012-02-25-es.

Corporación para la Asignación de Nombres y Números de Internet. (2012). Politica Uniforme de Solución de Controversias en Materia de Nombres de Dominio. https://www.icann.org/resources/pages/policy-2012-02-25-es.

Escartín Escudé, V. M. (2012). El arbitraje y otros medios alternativos de resolución de conflictos en el derecho administrativo. Revista Aragonesa de Administración Pública, (39-40), 101-163. https://dialnet.unirioja.es/servlet/artículo?codigo $=4078235$.

García Vidal, A. (2002). Derecho de Marcas e Internet. Tirant Lo Blanch.

López Ayllón, S. (2015). Sintesis del informe y de las recomendaciones en materia de justicia cotidiana. Centro de Investigación y Docencia Económicas (CIDE). https://imco.org.mx/wp-content/uploads/2015/04/Sintesis_JusticiaCotidiana-version-final.pdf.

Margáin, A. M. y Gurry, F. (2014). Memorándum de entendimiento entre la OMPI y el IMPI sobre prestación de servicios de métodos alternativos de solución de confictos. Instituto Mexicano de la Propiedad Industrial/Organización Mundial de la Propiedad Intelectual. https://www.gob.mx/cms/uploads/attachment/ file/100553/17_-_2014-11-24_Mou_IMPI-OMPI_Dispute_Resolution_Espan_ol.pdf.

Naciones Unidas. (1 de marzo de 2021). Operational Rates of Exchange. https:// treasury.un.org/operationalrates/OperationalRates.php.

Organización Mundial de la Propiedad Intelectual. (s.f.-a). Baremo de tasas y honorarios. https://www.wipo.int/amc/es/expert-determination/fees/.

Organización Mundial de la Propiedad Intelectual. (s.f.-b). Centro de Arbitraje y Mediación de la OMPI. http://www.wipo.int/amc/es/center/background.html.

Organización Mundial de la Propiedad Intelectual. (s.f.-c). Preguntas frecuentes. https://www.wipo.int/amc/es/center/faq/general.html.

Organización Mundial de la Propiedad Intelectual. (s.f.-d). WIPO Domain Name Dispute Resolution Statistics. https:/www.wipo.int/amc/en/domains/statistics.

Organización Mundial de la Propiedad Intelectual. (2016). Reglamento de Decisión de Experto. http://www.wipo.int/amc/es/expert-determination/rules/.

Organización Mundial de la Propiedad Intelectual. (2019). Reglamento Adicional de la Organización Mundial de la Propiedad Intelectual relativo al Reglamento de Solución Alternativa de Controversias .MX (LDRP). https://www.wipo.int/amc/ es/domains/rules/supplemental/mx.html.

Pampillo Baliño, J. P., Munive Páez, M. A., Reyes Velázquez, A., Servín González, O. y Suñé Llinás, E. (2012). Derecho informático e informática jurídica. Porrúa.

Pérez López, M. (2012). Estudio sobre las Salas Especializadas del Tribunal Federal de Justicia Fiscal y Administrativa. México. https://www.tfja.gob.mx/investigaciones/historico/pdf/estudiosobrelassalasespecializadastfffa.pdf.

Registry .MX. (s.f.-a). Politica de solución de controversias en materia de nombres 
de dominio para .MX (LDRP). https://www.dominios.mx/politicas-generales-de-nombre-de-dominio-mx/.

Registry.MX. (s.f.-b). Politicas generales de nombre de dominio .MX. https://www. dominios.mx/politicas-generales-de-nombre-de-dominio-mx/.

Registry.MX. (s.f.-c). Reglamento de la política de solución de controversias en materia de nombres de dominio para.MX. https://www.dominios.mx/politicas-generales-de-nombre-de-dominio-mx.

Tan, J. A. (2018). Guía de la OMPI sobre los métodos alternativos de solución de controversias (ADR) para las Oficinas de Propiedad Intelectual y los tribunales judiciales. Centro de Arbitraje y Mediación de la OMPI/Korean Intellectual Property Office. https://www.wipo.int/edocs/pubdocs/es/wipo_pub_guide_adr.pdf.

\section{Legislación citada}

Diario Oficial de la Federación. (2008). Acuerdo G/17/2008, mediante el cual se crea una Sala Regional en Materia de Propiedad Intelectual. Tribunal Federal de Justicia Fiscal y Administrativa. http://www.dof.gob.mx/nota_detalle.php?codigo $=5031951 \&$ fecha $=24 / 03 / 2008 \#:-:$ text $=$ SE $\% 20$ CREA $\% 20$ UNA $\% 20$ SALA\%20REGIONAL\%20EN\%20MATERIA\%20DE\%20PROPIEDAD\%20INTELECTUAL.,-Con\%20fundamento\%20en\&text=\%2D\%20 Adicionalmente $\% 20 \mathrm{habr} \% \mathrm{C} 3 \% \mathrm{~A} 1 \% 20$ una $\% 20$ Sala\%20Regional,Ciudad\%20de $\% 20 \mathrm{M} \% \mathrm{C} 3 \%$ A 9 xico\%2C\%20Distrito\%20Federal.

Diario Oficial de la Federación. (2020). Decreto promulgatorio del Protocolo por el que se sustituye el Tratado de Libre Comercio de América del Norte por el Tratado entre los Estados Unidos Mexicanos, los Estados Unidos de América y Canadá. http://dof.gob.mx/2020/SRE/T_MEC_290620.pdf.

Diario Oficial de la Federación. (2021). Acuerdo por el que se da a conocer la tarifa por los servicios que presta el Instituto Mexicano de la Propiedad Industrial. https://www.gob.mx/cms/uploads/attachment/file/614091/Acuerdo.Tarifa_Actualizacio_n_04.02.21_PDF.pdf.

Diario Oficial de la Federación, Constitución Política de los Estados Unidos Mexicanos, última reforma 11 de marzo de 2021.

Diario Oficial de la Federación, Ley Federal de Procedimiento Administrativo, última reforma 18 de junio de 2018.

Diario Oficial de la Federación, Ley Federal de Procedimiento Contencioso Administrativo, última reforma 27 de enero de 2017.

Diario Oficial de la Federación, Ley Federal de Protección a la Propiedad Industrial, publicada el 1 de julio de 2020, en vigor 5 de noviembre de 2020 .

Diario Oficial de la Federación, Ley Federal del Derecho de Autor, última reforma 1 de julio de 2020.

Diario Oficial de la Federación, Ley Orgánica del Tribunal Federal de Justicia Administrativa, publicada el 18 de julio de 2016.

Diario Oficial de la Federación, Reglamento Interior del Tribunal Federal de Justicia Administrativa, publicado el 17 de julio de 2020. 